\title{
BMJ Open Association of lifestyle modification and pharmacological adherence on blood pressure control among patients with hypertension at Kenyatta National Hospital, Kenya: a cross-sectional study
}

\author{
Samuel Kimani, ${ }^{1}$ Waithira Mirie, ${ }^{1}$ Margaret Chege, ${ }^{1}$ Okubatsion Tekeste Okube, ${ }^{2}$ \\ Samuel Muniu ${ }^{3}$
}

To cite: Kimani S, Mirie W, Chege M, et al. Association of lifestyle modification and pharmacological adherence on blood pressure control among patients with hypertension at Kenyatta National Hospital, Kenya: a crosssectional study. BMJ Open 2019;9:e023995. doi:10.1136/ bmjopen-2018-023995

- Prepublication history for this paper is available online. To view these files, please visit the journal online (http://dx.doi. org/10.1136/bmjopen-2018023995).

Received 7 May 2018

Revised 14 November 2018 Accepted 16 November 2018

Check for updates

(C) Author(s) (or their employer(s)) 2019. Re-use permitted under CC BY-NC. No commercial re-use. See rights and permissions. Published by BMJ.

${ }^{1}$ School of Nursing Sciences, University of Nairobi, Nairobi, Kenya

${ }^{2}$ Department of Nursing, Catholic University of Eastern Africa,

Nairobi, Kenya

${ }^{3}$ Policy Analysis, Aidspan, Nairobi, Kenya

Correspondence to

Dr Samuel Kimani;

tkimani@uonbi.ac.ke

\section{ABSTRACT}

Objective Association of lifestyle modification and pharmacological adherence among patients with hypertension attending a national referral hospital in Kenya.

Design Descriptive, cross-sectional.

Setting Medical wards and outpatient clinic of a national referral hospital.

Participants Patients $(\mathrm{n}=229)$ diagnosed with primary hypertension for at least 6 months.

Primary outcomes Clinical makers, cholesterol levels, anthropometrics, lifestyle/dietary habits adjusted for age, gender and education; antihypertensive adherence; views on prevention of hypertension and adequacy of hypertension information.

Results Ageing was associated with elevated diastolic blood pressure (BP) $(p<0.05)$, heart rate $(\mathrm{HR})$ and cholesterol. Females had higher body mass index (BMI). More males reported drinking alcohol and smoking $(p<0.001)$, especially the highly educated. Higher BPs were observed in smokers and drinkers $(p<0.05)$. Daily vegetables and fruits intake were linked to lower $B P, H R$ and BMI $(p<0.05)$. Intake of foods high in saturated fat and cholesterol were associated with raised HR $(p<0.05)$. Respondents on antihypertensive medication, those engaged in healthy lifestyle and took their prescribed medications had lower mean BPs than those on medication only (138/85 vs 140/90). Few respondents (30.8\%) considered hypertension as preventable, mainly the single and highly educated $(p<0.05)$. Respondents (53.6\%) believed they should stop taking their antihypertensive medication once hypertension is controlled.

Conclusion Missed targets for BP control and hypertension-related risks are associated with ageing, female gender, fast food and animal fat intake. Alcohol and smoking is common in males associated with poor BP control. Daily vegetables and fruits intake are associated with better $\mathrm{BP}$ control and overall hypertension risk reduction. Observed suboptimal BP control despite pharmacological adherence suggests lifestyle modification is needed besides antihypertensive medication. Interventions should address modifiable risk factors aggravated by age and adverse lifestyles through

\section{Strengths and limitations of this study}

- This is the first study to objectively demonstrate the link between alcohol, smoking, dietary practices and blood pressure control in individuals with established hypertension (HTN) in Kenya.

- The identification of a critical knowledge gap among individuals diagnosed with HTN on the preventable nature of HTN and the requirement for lifelong treatment of HTN.

- The focus on the need for respect and authority for Kenyan health professionals in the management and prevention of HTN; putting the responsibility on them to lead in campaigns against HTN.

- The study was limited by its cross-sectional design.

- Assessment of smoking, alcohol consumption and dietary habits capture information at one point in time potentially missing variability in health behaviours and medication practices.

adopting combined lifestyle modification, pharmacological adherence and tailored expert delivered hypertensionrelated information.

\section{INTRODUCTION}

Hypertension is a leading risk factor for morbidity and mortality in adult populations globally. Hypertension-related morbidity is implicated in cardiovascular derangement, chronic kidney disease and diabetes that cumulatively account for over $40 \%$ of global deaths. ${ }^{1}$ Recent reports indicate that hypertension is the single most important risk factor for ill health contributing to higher burden of global disability-adjusted life-years. ${ }^{2}$ The prevalence and burden of hypertension has gained unprecedented momentum in low-income and middle-income countries, at the same time that the problem has either stabilised or declined in high-income nations. 
Some reports suggest that the decline in hypertension in high-income countries is the result of focused preventive and management strategies. ${ }^{34}$ In 2015, high-income countries had recorded the lowest blood pressure while the highest levels were observed in sub-Saharan Africa. ${ }^{3}$ The unpreceded high rates of hypertension-related non-communicable diseases are attributed to epidemiological, demographic and nutritional transitions in sub-Saharan Africa. ${ }^{3}$

Although hypertension has progressively become a major threat to health and well-being in sub-Saharan Africa, the crisis is yet to receive commensurate attention and investment response ${ }^{5}$ from critical actors, programmers, planners and implementers. Sadly, the region reports the highest prevalence of hypertension, notably $46 \%$ among adults aged 25 years and above, compared with $35 \%$ in the Americas and other high-income countries. ${ }^{6}$ The magnitude of hypertension in Africa increased from 54.6 million in 1990 to 92.3 million in 2000 , and 130.2 million in 2010 with projections estimated at 216.8 million by 2030 if the current trajectory is not interrupted. $^{7}$

WHO has adduced the major risk factors for hypertension broadly categorised into behavioural, metabolic, social determinants and cardiovascular diseases-linked. ${ }^{8}$ Hypertension-related behavioural risk factors include unhealthy diet, tobacco, physical inactivity and harmful use of alcohol. ${ }^{8-10}$ The metabolic risk factors include high blood pressure, obesity, diabetes and elevated blood lipids. ${ }^{810}$ The aforementioned risk factors have also been reported in studies conducted in Kenya. ${ }^{11-14}$ Furthermore, the social determinants associated with hypertension are closely linked to development and modernisation, which include globalisation, urbanisation, ageing, education and housing. ${ }^{85-17}$ Importantly, the hypertension-linked risk factors that are attributed to cardiovascular-related complications notably heart attack, stroke, heart failure and kidney diseases are some of the major causes of morbidity and mortality in adult populations. ${ }^{8}$

The Kenyan healthcare system is primed to respond to management and prevention of hypertension through its comprehensive structure. It consists of three subsystems namely, public, commercial private and faith-based organisations. The public sector is the largest sector with high number of facilities, manpower, patient flow and large financing. The financing mechanisms for health is through taxation, the National Health Insurance Fund, private health insurances, employer schemes, community-based health financing, user fees (out-of-pocket expenses), development partners and non-governmental organisations. ${ }^{18}$ Government spending on healthcare is approximately $6 \%$ of GDP with about $25 \%$ of Kenyans covered by public, private or community-based health insurance schemes. However, with substantially low numbers of citizenry covered with health insurance, the amount of out-of-pocket spending remains high resulting in a high financial burden as well as posing a significant barrier to accessing healthcare. ${ }^{18}$ Administratively, the public health system is structured into six levels including: teaching and referral hospitals (level 6), provincial referral (level 5), county and subcounty (level 4), health centres (level 3), dispensary (level 2) and community (level 1). ${ }^{19}$ However, disparities regarding the services offered in the facilities exists, especially in rural areas where the poor majority live lacking access to specialised treatment including hypertension detection and treatment. Kenyatta National Hospital (KNH), where this study was conducted, is the largest national referral and teaching hospital in Kenya with bed capacity of 2000 distributed across 50 wards. The hospital provides health services to the bulk of patients including those with hypertension. The services at KNH span outpatient and inpatient including pharmacological and lifestyle modification interventions. The management interventions for hypertension are offered and supported by specialty physicians, nurses, nutritionists, laboratory professionals and a battery of other healthcare providers. To mitigate hypertension-related consequences, risk factors are identified and addressed as early as possible. Blood pressure surveillance/monitoring and treatment is carried out for persons with hypertension to prevent complications and allow for a near-normal life. Thus, the aforesaid risk factors are addressed through adherence to pharmacological therapy or lifestyle modification or the combination of both. ${ }^{720-22}$

Interventions that promote adherence to lifestyle modification and pharmacological therapy are critical in the management and prevention of hypertension and its associated complications. The interventions complement each other, with dual benefits. Healthy patterns consist of daily habits performed deliberately for the long term (months to years). These lifestyle habits include healthy nutrition and moderate alcohol, physical activity, not smoking and maintenance of optimal body weight and have been associated with controlling, moderating and lowering blood pressure levels. ${ }^{23-26}$ The non-pharmacological interventions can either be adopted as an initial treatment, or in combination with drug therapy. Indeed, the adoption of healthy lifestyle behaviours has been credited with reduction in the use of antihypertensive medications, ${ }^{27}$ increased fitness, health and productivity. Beyond lifestyle modification, pharmacological therapy also plays a critical role in modulating and lowering blood pressure in individuals with hypertension seeking professional interventions for the disease. The classes of antihypertensive medications that are used in managing patients with hypertension include ACE inhibitors and angiotensin receptor blockers both of which are effective and well-tolerated options for starting and maintaining antihypertensive regime. Additionally, diuretics, calcium channel blockers, beta-receptor blockers and thiazides have blood pressure-lowering effects and have been used extensively. These antihypertensive drugs are used alone or in combination depending on the patient response and blood pressure control achieved..$^{28-30}$ The antihypertensive medications are found in private specialist 
clinics, as well as in level 4, 5 and 6 public hospitals in Kenya. Furthermore, hypertension-related interventions are shared with patients through health education, print, electronic and direct clinician-patient interactions. Once initiated, it is important to monitor the effectiveness of the interventions through routine reviews and measurement of clinical markers including anthropometrics and blood pressure levels. Studies on whether patients with hypertension adhere to lifestyle modifications with the same enthusiasm as pharmacological therapy are lacking in Kenya. Therefore, we sought to investigate the association of lifestyle modification and pharmacological adherence on blood pressure control among patients with hypertension at the largest level 6 hospital in Kenya.

\section{METHODS AND MATERIALS \\ Study setting}

This study was conducted at KNH, a level 6 referral and teaching public health facility in Nairobi. KNH offers both outpatient and inpatient specialty services including emergency, obstetrics and gynaecology, medical, surgical, oncology, cardiology, diabetes, hypertension and paediatrics medicine and related interventions among others. The study included patients with hypertension attending the medical outpatient clinic as well as those admitted in the medical wards.

\section{Study design and sampling}

The study used a descriptive cross-sectional design and included randomly selected respondents $(n=229)$ from the medical outpatient clinic and the medical wards. During the study period, the outpatient clinic offered services to 1760 patients while the medical wards admitted 448 patients with hypertension. Accordingly, based on the adopted formula from Mugenda and Mugenda, ${ }^{31}$ an estimated sample size of 256 was calculated. Through proportionate calculation, 205 respondents were sampled from the outpatient clinic, while 51 were sampled from the inpatient wards. Systematic random sampling was applied to select the study respondents once their files were obtained and scrutinised for the inclusion criteria (figure 1). A total of 2208 patients were identified and divided by the minimum adjusted sample size of 256 to arrive at a sampling interval of 8 . Thereafter, every eighth patient was included in the sample until the desired sample size was attained. Twenty-seven respondents had incomplete information and were excluded from the study.

\section{Data collection}

Data were collected using a researcher-assisted semi-structured questionnaire. The questionnaire was pretested on patients $(n=10)$ with hypertension admitted to one medical ward at $\mathrm{KNH}$. The results from the pretest were analysed and used to determine the final questionnaire. The questionnaire consisted of closed and open-ended questions that captured information related to: demographic characteristics, knowledge about hypertension,

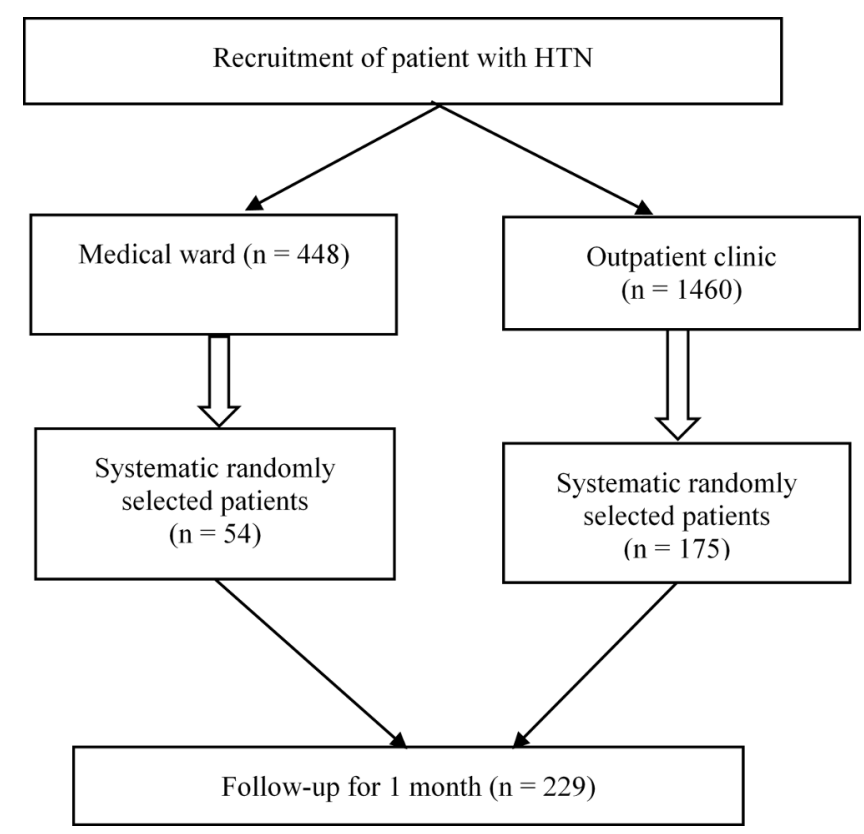

Figure 1 Flow chart for the study inclusion criteria. A total of 229 respondents were included in the study. HTN, hypertension.

management of hypertension, lifestyle factors, views on hypertension and its management, adherence to medication and lifestyle changes as well as clinical and anthropometric parameters. Eligible respondents were interviewed and examined for inclusion criteria by trained nurses as research assistants. The criteria for inclusion in the study included: a diagnosis of essential hypertension, on antihypertensive medication and/or lifestyle modification interventions for elevated blood pressure $(\geq 140 / 90 \mathrm{~mm} \mathrm{Hg})$, attending follow-up at medical outpatient clinic for at least 6 months or admitted in the respective medical ward. The clinical and anthropometric measurements were performed after informed consent was obtained. The cholesterol levels were obtained from the patient file and recorded in the study checklist.

Clinical variables. Hypertension was defined according to the Seventh Report of the Joint National Committee on Prevention, Detection, Evaluation, and Treatment of High Blood Pressure (JCN7) criteria as having a systolic blood pressure of $\geq 140 \mathrm{~mm} \mathrm{Hg}$ or a diastolic blood pressure of $\geq 90 \mathrm{~mm} \mathrm{Hg}$ or being on medication for hypertension. ${ }^{2}$ In this study, respondents with systolic blood pressure of $<140 \mathrm{~mm} \mathrm{Hg}$ and a diastolic pressure of $<90 \mathrm{~mm} \mathrm{Hg}$ were considered controlled. Similarly, those with systolic blood pressure of $>140 \mathrm{~mm} \mathrm{Hg}$ and a diastolic pressure of $>90 \mathrm{~mm} \mathrm{Hg}$ were considered not controlled. Respondents were requested to sit and relax in a quiet room for $5 \mathrm{~min}$ before their radial arterial pulse and brachial blood pressure were taken on the right arm. Measurements were obtained twice in the sitting position for outpatients or supine position for hospitalised patients using appropriate cuff sizes. Blood pressure and heart rate were measured with an automatic blood pressure monitor (OMRONM4, Omron Healthcare GmbH, 


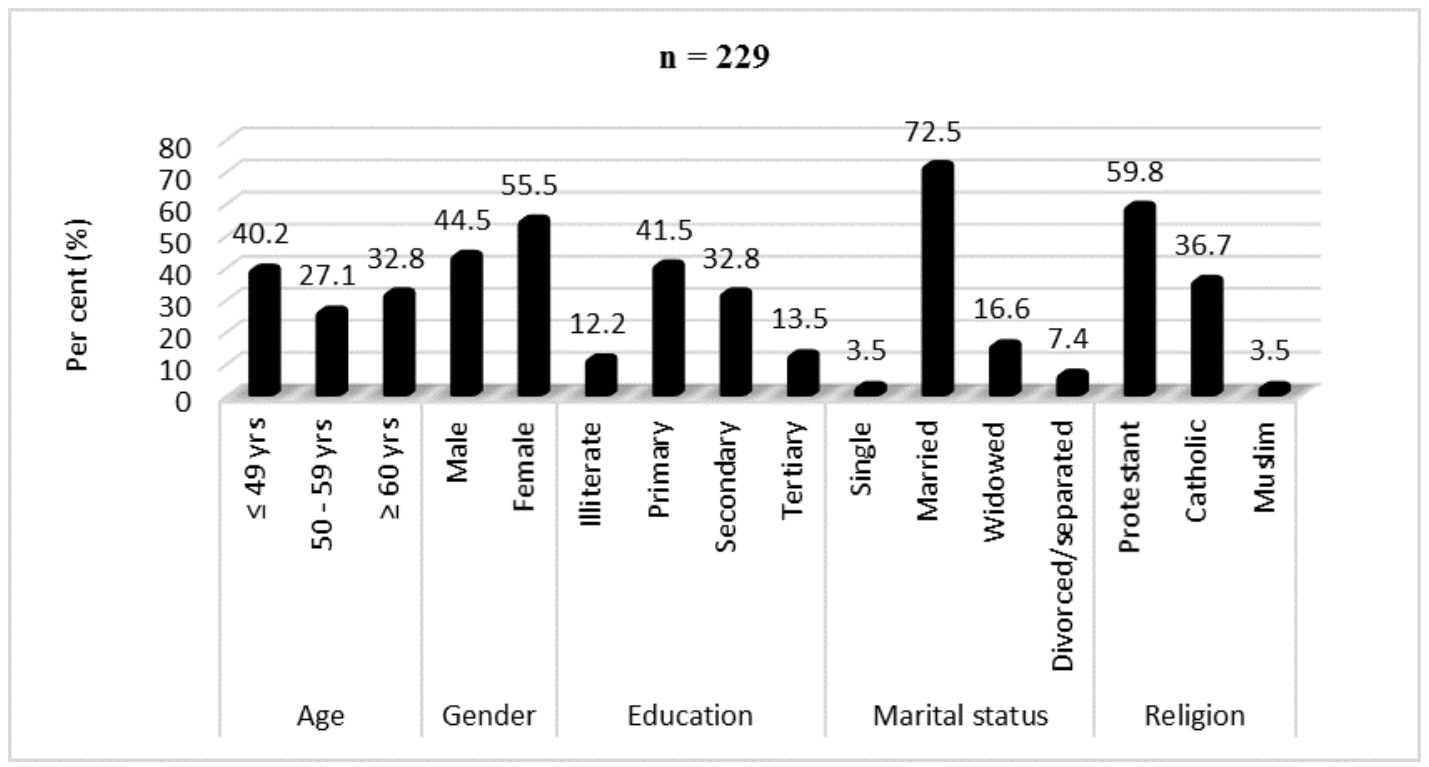

Figure 2 Demographics of the respondents. A higher proportion of the respondents were females (55.5\%), below 60 years (67.3\%), married (72.5\%), Protestants (59.8\%) with primary level of education (41.5\%).

Hamburg, Germany), with the final value calculated as the average of two consecutive measurements in the same arm. Total cholesterol measures were obtained from the patient file. All measurements were recorded in the study checklist.

Sociodemographic and lifestyle variables. Sociodemographic information, specifically age, marital status, level of education, history of smoking and consumption of alcohol were obtained from each respondent using a researcher-assisted standardised questionnaire.

Food intake and dietary patterns. Self-reported information about food consumption patterns was collected using a questionnaire derived from the Diet History Questionnaire-NIH ${ }^{32}$ customised for use in Kenyan settings. Researchers assisted the patient in completing the questionnaire. The questionnaire assessed dietary patterns and modification made by the patients since they were diagnosed with hypertension. The main focus of the questionnaire was general dietary patterns in regard to frequency (daily, weekly, monthly), and amount of meat, vegetables, fruits and beverages such as alcohol intake.

Anthropometric variables. Anthropometric measurements including weight, height, body mass index (BMI) and waist circumference were measured using standardised methods. Waist circumference was determined by measuring the waist at midpoint between iliac crest and lower border of the tenth rib, with an average of three measurements considered as the final value. Using the International Diabetes Federation criteria ${ }^{33}$ that is gender-specific and ethnic-specific, a waist circumference of $\geq 94 \mathrm{~cm}$ for men and $\geq 80 \mathrm{~cm}$ for women were considered abnormally high. BMI was calculated based on weight in kilogram divided by the square of height in metres $(\mathrm{kg} /$ $\mathrm{m}^{2}$ ). The weight and height were obtained using weighing scale with a stadiometer (Seca $\mathrm{GmbH}$, Germany) and these values were used to calculate the BMI. The height was measured and recorded to the nearest $0.1 \mathrm{~cm}$, while the waist circumference was measured with a non-stretchable tape measure to the nearest $0.1 \mathrm{~cm}$.

Adherence to antihypertensive medications. Adherence to antihypertension medications was determined by asking the patient to report the name, dose and frequency of prescribed medications they took during the period preceding the appointment. This information was validated by checking the clinical records and reconciling the number of tablets that had been taken and the number remaining in the patients pill pack. Thereafter, the information was recorded in patient medical file.

Knowledge on hypertension and its management. Data on hypertension and its management were obtained using questions targeting the patients' views regarding the preventable nature of hypertension, adherence to antihypertensive medications, the duration the treatment last and how information on hypertension should be shared by the clinician.

\section{Data analyses}

Data were organised, screened and checked for completeness. Data were coded and entered into the computer and cross-checked with the original source for accuracy. Analyses were performed using computer software (SPSS V.22). Descriptive and inferential statistics were generated, interpreted and reported. Specifically, descriptive data were analysed using proportions and summarised in frequency tables. Fisher's exact test and $\mathrm{X}^{2}$ test of independence were used to establish the relationships between sociodemographic variables (age, gender, education, marital status and religion) and smoking, alcohol consumption, respondent's views on prevention and availability of information on hypertension. Analysis of variance was performed to establish differences between clinical variables (blood pressure, heart rate), total cholesterol and anthropometrics (BMI, waist circumference) measurement across age, gender and dietary patterns. Logistic regression was performed using forward 
Table 1 High clinical, anthropometrics and cholesterol measurements are associated with 50-59 years age group while anthropometrics are higher in females

\begin{tabular}{|c|c|c|c|c|c|c|c|c|c|}
\hline \multirow[b]{2}{*}{ Measurement } & \multicolumn{3}{|c|}{ Age (years)* } & \multirow[b]{2}{*}{$P$ value } & \multicolumn{2}{|c|}{ Gender† } & \multirow[b]{2}{*}{$P$ value } & \multirow[b]{2}{*}{ Overall mean } & \multirow[b]{2}{*}{ SD } \\
\hline & $\geq 49$ & $50-59$ & $\geq 60$ & & Male & Female & & & \\
\hline Mean SBP (mm Hg) & 138.5 & 142.5 & 138.1 & 0.142 & 140.2 & 138.8 & 0.462 & 139.45 & 14.1 \\
\hline Mean HR (beats/min) & 79.42 & $84.7 \ddagger$ & 82.46 & 0.002 & 81.96 & 81.75 & 0.87 & 81.85 & 9.3 \\
\hline Mean BMI $\left(\mathrm{kg} / \mathrm{m}^{2}\right)$ & 28.81 & 29.56 & 28.43 & 0.295 & 28.25 & 29.39 & 0.045 & 28.88 & 4.2 \\
\hline Hip (cm) & 97.44 & 97.52 & 91.07 & 0.341 & 92.13 & 98.15 & 0.135 & 95.55 & 29.1 \\
\hline Total cholesterol (mmol/L) & 5.42 & $5.76 \ddagger$ & 5.34 & 0.046 & 5.37 & 5.6 & 0.105 & 5.5 & 0.85 \\
\hline
\end{tabular}

The values in bold emphasise where the $p$-value is statistically significant, that is less than 0.05 .

*One-way analysis of variance.

†Independent samples t-test.

$\ddagger$ The group contributing the difference.

BMI, body mass index; DBP, diastolic blood pressure; HR, heart rate; SBP, systolic blood pressure.

selection to determine factors associated with blood pressure control. The removal and inclusion of probabilities into the models were set at $p$ values of 0.20 and 0.10 , respectively. The cut-off point for the level of significance was set at $\mathrm{p}<0.05$.

\section{Ethical consideration}

Prior to the commencement of data collection, verbal and written consent was obtained from patients with hypertension who met the inclusion criteria following a detailed explanation about the study goals and procedures.

\section{Patient and public involvement}

Patients and members of the public were not involved in developing the research questions and design of the study; however, the recruitment of respondents involved patients and members of the public after a comprehensive explanation of the study including obtaining consent. The results will be disseminated to the public during health message sharing sessions in the outpatient clinic.

\section{RESULTS}

\section{Demographic characteristics of the respondents}

The sociodemographic characteristic (age, gender, educational attainment, marital status and religion) of

Table 2 Relationship between BMI and blood pressure control among respondents

\begin{tabular}{|c|c|c|c|c|c|c|}
\hline \multirow[b]{2}{*}{$\begin{array}{l}\text { Blood } \\
\text { pressure }\end{array}$} & \multicolumn{2}{|c|}{ Frequency } & \multirow{2}{*}{$\begin{array}{l}\text { Mean } \\
\text { systolic } \\
\text { pressure }\end{array}$} & \multirow{2}{*}{$\begin{array}{l}\text { Mean } \\
\text { diastolic } \\
\text { pressure }\end{array}$} & \multicolumn{2}{|l|}{ BMI } \\
\hline & $\mathbf{n}$ & $\begin{array}{l}\text { Per cent } \\
\text { (\%) }\end{array}$ & & & $\begin{array}{l}\text { Mean } \\
\text { BMI }\end{array}$ & $P$ value \\
\hline Controlled & 78 & 34.80 & 124.85 & 78.16 & 27.89 & 0.008 \\
\hline $\begin{array}{l}\text { Not } \\
\text { controlled }\end{array}$ & 146 & 65.20 & 147.24 & 94.99 & 29.46 & \\
\hline Total & 224 & 100.00 & & & & \\
\hline
\end{tabular}

Analysis with independent samples t-test. Successful blood pressure control was defined as $<140 \mathrm{~mm} \mathrm{Hg}$ systolic and $<90 \mathrm{~mm} \mathrm{Hg}$ diastolic. BMI, body mass index. the respondents are presented in figure 2. The sample was fairly young $(40.2 \%$ aged below 50 years) and female $(55.5 \%)$, had limited educational attainment (primary or less; $53.5 \%)$, were married $(72.5 \%)$ and of the Christian faith $(96.5 \%)$. Figure 2 provides more details on the sociodemographic categories.

Clinical, anthropometric and total cholesterol measurements in respondents with hypertension

The clinical makers, anthropometrics and total cholesterol levels stratified by age and gender are presented in table 1 . The overall mean value and SD for these variables included: systolic blood pressure of $139.45 \pm 14.1 \mathrm{~mm}$ $\mathrm{Hg}$, diastolic blood pressure $89.18 \pm 12.8 \mathrm{~mm} \mathrm{Hg}$ and a heart rate of $81.8 \pm 9.3($ mean \pm SD) beats per minute. The mean BMI was $28.88 \pm 4.2($ mean $\pm \mathrm{SD}) \mathrm{kg} / \mathrm{m}^{2}$, the mean waist circumference of $81.45 \pm 24.9 \quad($ mean \pm SD) and hip circumference at $95.55 \pm 29.1($ mean $\pm \mathrm{SD}) \mathrm{cm}$, respectively. Further analysis stratified by age and gender (table 1) revealed that respondents aged $50-59$ years had significantly higher DBP $\left(\mathrm{F}_{2,220}=3.248 ; \mathrm{p}<0.05\right) \mathrm{mm} \mathrm{Hg}$, heart rate $\left(\mathrm{F}_{2,212}=6.194 ; \mathrm{p}<0.05\right)$ and total cholesterol $\left(\mathrm{F}_{2,145}=3.136 ; \mathrm{p}<0.05\right) \mathrm{mmol} / \mathrm{L}$, respectively. In addition, females had significantly $\left(\mathrm{t}_{2}=2.021 ; \mathrm{p}<0.05\right)$ higher BMI compared with males.

Among the respondent whose blood pressure was measured, only $34.8 \%$ had their blood pressure controlled (table 2). Successful blood pressure control was defined as $<140 \mathrm{~mm} \mathrm{Hg}$ systolic and $<90 \mathrm{~mm} \mathrm{Hg}$ diastolic. Further analysis with independent samples t-test revealed a statistically significant association between BMI and blood pressure control. Respondents with lower BMI $\left(27.89 \mathrm{~kg} / \mathrm{m}^{2}\right)$ were more likely to have their blood pressure controlled $(\mathrm{t}=2.686$, $\mathrm{df}=216, \mathrm{p}=0.008$ ) compared with their counterparts with higher BMI $\left(29.46 \mathrm{~kg} / \mathrm{m}^{2}\right)$.

\section{Relationship between lifestyle factors and hypertension}

Self-reported smoking and alcohol consumption among respondents relative to gender, educational attainment 


\begin{tabular}{|c|c|c|c|c|c|c|c|}
\hline \multirow[b]{2}{*}{ Variable } & \multicolumn{2}{|l|}{ Smoke } & \multirow[b]{2}{*}{$P$ value } & \multicolumn{2}{|c|}{ Take alcohol } & \multirow[b]{2}{*}{ Total } & \multirow[b]{2}{*}{$P$ value } \\
\hline & Yes (\%) & No (\%) & & Yes (\%) & No (\%) & & \\
\hline Gender & & & 0.000 & & & & 0.001 \\
\hline Male & $17(16.7)$ & 85 (83.3) & & $22(21.6)$ & $80(78.4)$ & $102(100)$ & \\
\hline Female & $2(1.6)$ & $125(98.4)$ & & $8(6.3)$ & $119(93.7)$ & $127(100)$ & \\
\hline Total & $19(8.3)$ & $210(91.7)$ & & $30(13.1)$ & $199(86.9)$ & 229 (100) & \\
\hline Education & & & 0.921 & & & & 0.000 \\
\hline None-primary & $10(8.1)$ & $113(91.9)$ & & $7(5.7)$ & $116(94.3)$ & $123(100)$ & \\
\hline Postprimary & $9(8.5)$ & 97 (91.5) & & $23(21.7)$ & $83(78.3)$ & $106(100)$ & \\
\hline Total & $19(8.3)$ & $210(91.7)$ & & $30(13.1)$ & $199(86.9)$ & $229(100)$ & \\
\hline Blood pressure control & & & 0.808 & & & & 0.012 \\
\hline Controlled & $6(7.7)$ & 72 (92.3) & & $4(5.1)$ & 74 (94.9) & 78 (100) & \\
\hline Not controlled & $13(8.9)$ & $133(91.1)$ & & $26(17.8)$ & $120(82.2)$ & $146(100)$ & \\
\hline Total & 19 (8.5) & 205 (91.5) & & 30 (13.4) & 194 (86.6) & $224(100)$ & \\
\hline
\end{tabular}

The values in bold emphasise where the $p$-value is statistically significant, that is less than 0.05 .

Analysis with $\mathrm{X}^{2}$ test of independence.

Successful blood pressure control was defined as $<140 \mathrm{~mm} \mathrm{Hg}$ systolic and $<90 \mathrm{~mm} \mathrm{Hg}$ diastolic.

and blood pressure control are presented (table 3). Overall mean values for the sample included; $13.1 \%$ had a history of drinking alcohol and $8.3 \%$ smoked. Many of those who reported smoking $(31.6 \%)$ had done so for over 10 years. A majority $(94.4 \%)$, however had not attempted to stop despite having been advised $(89.5 \%)$ by a doctor. Further analyses observed that males were more likely to report smoking compared with females $\left(x^{2}=16.93\right.$; $\mathrm{df}=1 ; \mathrm{p}<0.001)$. Self-reported alcohol consumption was associated with male gender $(\mathrm{p}<0.001) .\left(\mathrm{x}^{2}=11.59\right.$; $\mathrm{df}=1$; $\mathrm{p}<0.001)$, higher educational attainment $\left(\mathrm{x}^{2}=12.82 ; \mathrm{df}=1\right.$; $\mathrm{p}<0.001)$ and poor blood pressure control $\left(x^{2}=7.047\right.$, $\mathrm{df}=1, \mathrm{p}=0.012$ ). The association between smoking and blood pressure did not yield any statistically significant difference.

\section{Adherence to pharmacological therapy and lifestyle modification among respondents}

Adherence to taking prescribed medication for hypertension and heart healthy lifestyle practices are presented (figure 3). A majority of the respondents $(85.2 \%)$ took medication as prescribed, $75.5 \%$ consumed vegetables and $44.1 \%$ ate fruits daily. The majority of the respondents $(55.5 \%)$ never ate fast foods, but $31 \%$ consumed a meal with high animal fat content on daily basis. Respondents who

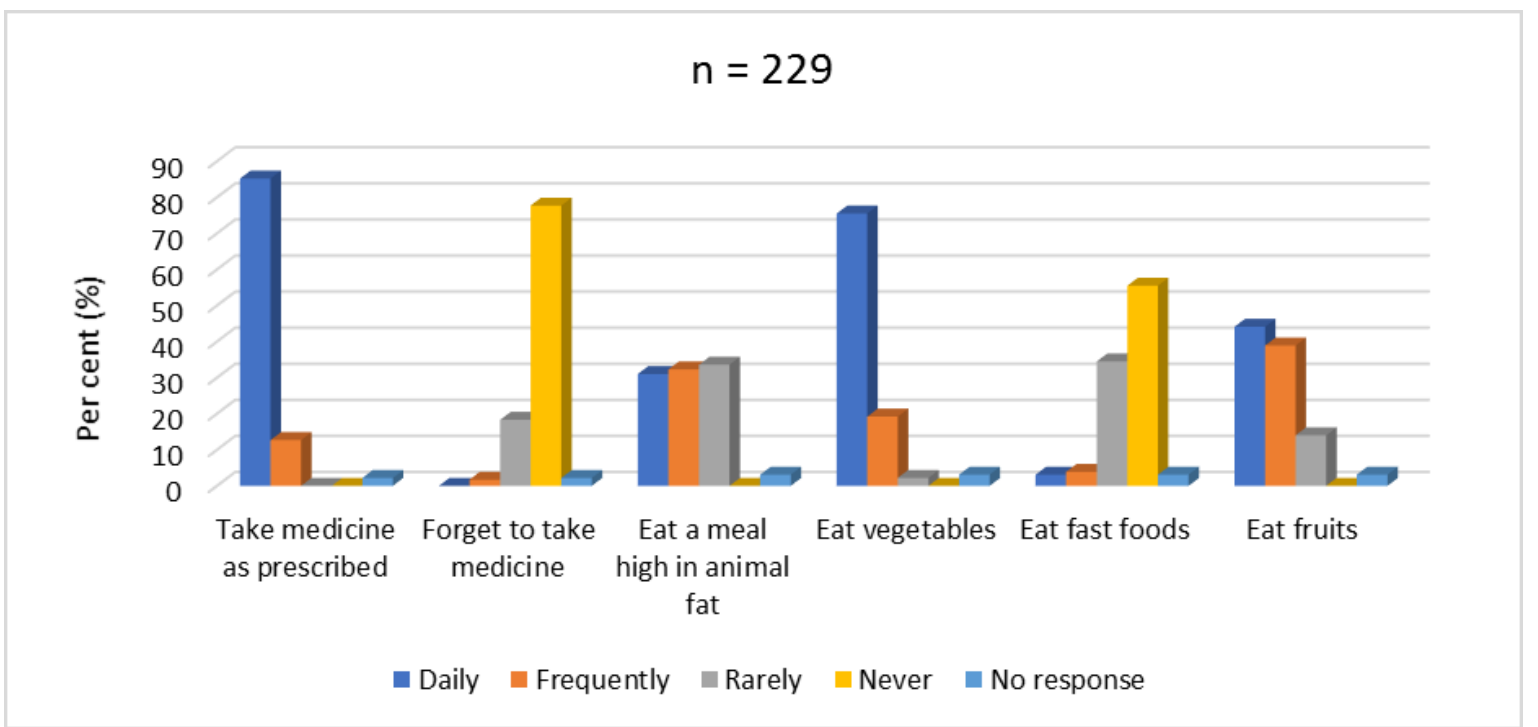

Figure 3 Adherence to pharmacological therapy and lifestyle modification. A higher proportion of the respondents took medicine as prescribed (85.2\%), never forgot to take medicine $(77.7 \%)$, consumed fruits $(44.1 \%)$ and vegetables daily $(75.7 \%)$ and never ate fast foods (55.5\%). 
Table 4 Respondents who adhered to pharmacological therapy alone showed pattern of high blood pressure compared with those on combined drugs and lifestyle modification

\begin{tabular}{|c|c|c|c|c|c|c|c|c|}
\hline Intervention & $\mathbf{N}$ & $\begin{array}{l}\text { Mean } \\
\text { systolic } \\
\text { pressure }\end{array}$ & SD & $P$ value & $\mathbf{N}$ & $\begin{array}{l}\text { Mean } \\
\text { diastolic } \\
\text { pressure }\end{array}$ & SD & $P$ value \\
\hline Yes & 192 & 140.08 & 13.802 & & 191 & 88.92 & 11.848 & \\
\hline No & 29 & 136.00 & 14.868 & & 29 & 91.53 & 17.572 & \\
\hline Total & 221 & 139.54 & 13.980 & & 191 & 88.92 & 11.848 & \\
\hline Yes & 27 & 137.96 & 12.556 & & 27 & 84.93 & 8.965 & \\
\hline No & 197 & 139.65 & 14.310 & & 196 & 89.76 & 13.165 & \\
\hline Total & 224 & 139.45 & 14.095 & & 223 & 89.18 & 12.812 & \\
\hline $\begin{array}{l}\text { Pharmacological and lifestyle } \\
\text { adherence } †\end{array}$ & & & & 0.706 & & & & 0.098 \\
\hline Total & 224 & 139.45 & 14.095 & & 223 & 89.18 & 12.812 & \\
\hline
\end{tabular}

*Respondents fulfilled five criteria: no smoking, no alcohol, rarely ate food high in animal fat, eat fruits daily and eat vegetables daily. †Respondents fulfilled six criteria: no smoking, no alcohol, rarely ate food high in animal fat, eat fruits daily, eat vegetables daily and took prescribed medicines daily.

reported adherence to medication in addition to adherence to heart healthy lifestyle behaviours were more likely to have lower blood pressure than those who only took medications $(138.42 / 85.08 \mathrm{~mm} \mathrm{Hg}$ vs $140.08 / 88.92 \mathrm{~mm} \mathrm{Hg}$ ); however, these differences were not statistically significant (table 4 ).

Relationship between clinical, cholesterols and anthropometric measurements and dietary practices among respondents

The clinical, cholesterol and anthropometric measurements relative to dietary patterns among respondents are presented (table 5). Respondents who reported consuming vegetables on daily basis had lower systolic blood pressures $\left(\mathrm{F}_{2,216}=3.490 ; \mathrm{p}<0.05\right)$ and diastolic blood pressures $\left(\mathrm{F}_{2,215}=3.793 ; \mathrm{p}<0.05\right)$. Similarly, lower heart rate was observed with those who consumed fruits $\left(\mathrm{F}_{2,207}=10.845 ; \mathrm{p}<0.001\right)$ and vegetables $\left(\mathrm{F}_{2,207}=13.025\right.$; $\mathrm{p}<0.001)$ on daily basis. Additionally, respondents with low BMI were associated with daily consumption of fruits $\left(\mathrm{F}_{2}\right.$, $\left.{ }_{211}=4.582 ; \mathrm{p}<0.05\right)$ and vegetables $\left(\mathrm{F}_{2,211}=5.184 ; \mathrm{p}<0.05\right)$, while low cholesterol levels were linked to daily consumption of fruits alone $\left(\mathrm{F}_{2,140}=3.499 ; \mathrm{p}<0.05\right)$. Adverse health behaviours including daily consumption of fast foods ( $\mathrm{F}$ $\left.{ }_{3,206}=3.196 ; \mathrm{p}<0.05\right)$ and meals high in animal fats $\left(\mathrm{F}_{2}\right.$, $\left.{ }_{207}=7.047 ; \mathrm{p}<0.001\right)$ were linked to higher heart rate.

\section{Logistic regression with risk factors associated with hypertension}

A logistic regression was performed with blood pressure control as the dependent variable and alcohol consumption, and BMI as predictor variables (table 6). The logistic model yielded statistical significance $\left(x^{2}=16.418, d f=3, p=0.001\right)$. Individuals who consumed alcohol were $77 \%$ less likely to have blood pressure controlled ( $\mathrm{OR}=0.229$ (95\% CI 0.066 to 0.793$), \mathrm{p}=0.02$ ). Individuals who had higher BMI were $8 \%$ less likely to have blood pressure controlled $(\mathrm{OR}=0.919$ (95\% CI 0.855 to 0.988$), \mathrm{p}=0.023$ ).

\section{Views regarding prevention of hypertension among the respondents}

The views of respondents on prevention of hypertension relative to their sociodemographic characteristic are shown in table 7 . Overall, only $30.8 \%$ of respondents viewed hypertension as preventable (table 7). Further analyses with $\mathrm{X}^{2}$ test of independence revealed the respondents who reported their marital status as single $\left(\mathrm{x}^{2}=13.53 ; \mathrm{p}<0.05\right)$ and had higher educational attainment $\left(\mathrm{x}^{2}=2.16, \mathrm{df}=6 ; \mathrm{p}<0.001\right)$ were more likely to hold the view that hypertension is preventable.

Views on availability of adequate information on hypertension The respondents' views on availability of adequate information on hypertension relative to their sociodemographic characteristic are shown in table 8. Overall, only $16 \%$ of respondents viewed the available information on hypertension as adequate. Those of higher educational attainment, were more likely $\left(x^{2}=16.07 ; \mathrm{p}<0.05\right)$ to report that hypertension information was inadequate compared with those with primary and no formal education.

Views on dissemination of information regarding management of hypertension

The respondents' views on dissemination of information on the management of hypertension is shown table 9 . Once their blood pressure was controlled, the vast 
Table 5 Daily consumption of vegetables and fruits are associated with low heart rate, body mass index, blood pressure and cholesterol while fast foods and animal fat are linked to increased heart rate

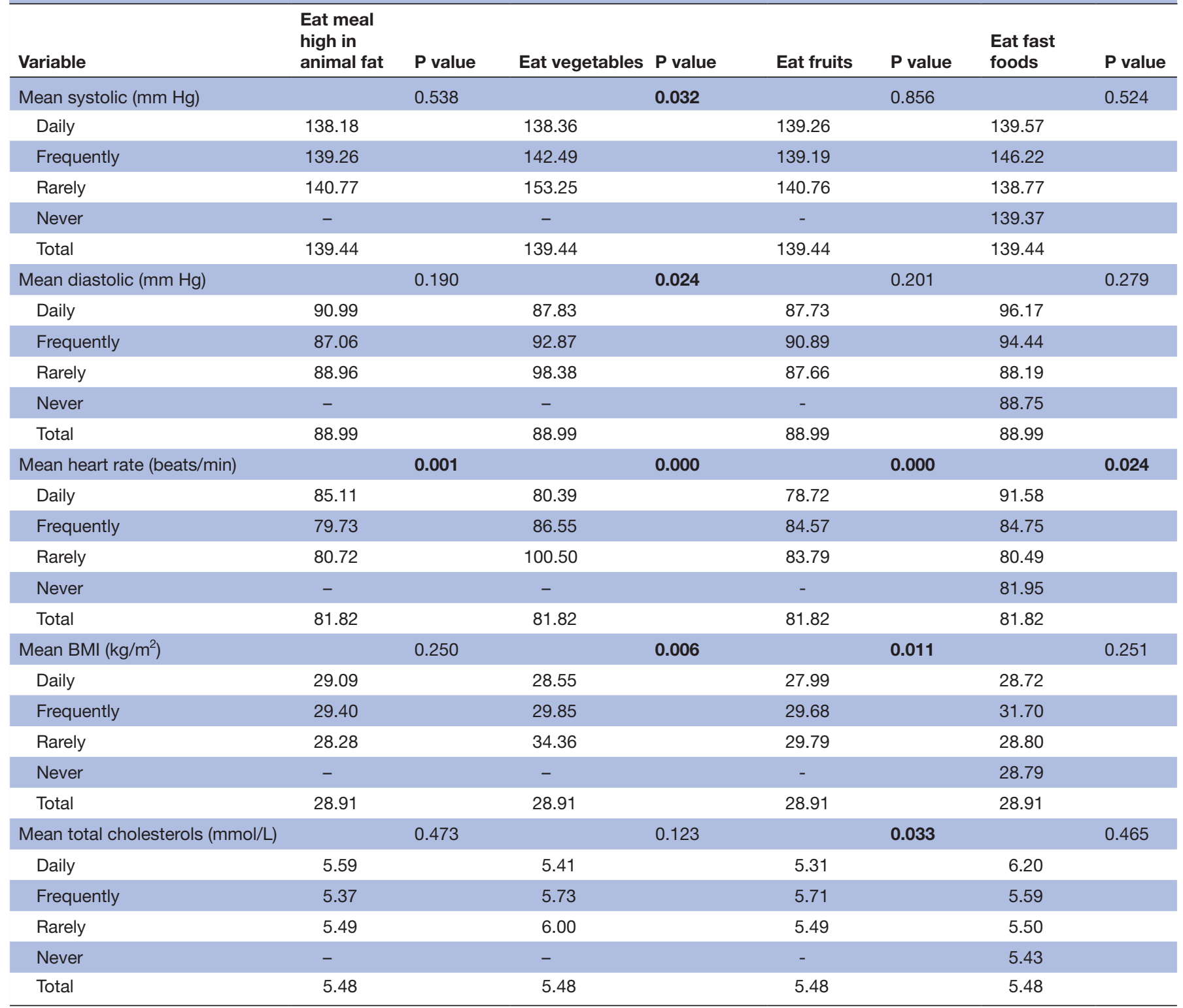

The values in bold emphasise where the $p$-value is statistically significant, that is less than 0.05 .

The relationship between clinical, anthropometric measurements and dietary practices is presented in this table.

Analysis with one-way analysis of variance.

BMI, body mass index.

majority of respondents (72.4) believed that medication should be stopped or they did not know what to do. The respondents preferred dissemination of medical information about hypertension to be done through radio

\section{Table 6 Risk factors associated with hypertension in binary logistic regression}

\begin{tabular}{|c|c|c|c|c|c|c|c|c|}
\hline \multirow[b]{2}{*}{ Risk factor } & \multirow[b]{2}{*}{ B } & \multirow[b]{2}{*}{ SE } & \multirow[b]{2}{*}{ Wald } & \multirow[b]{2}{*}{ df } & \multirow[b]{2}{*}{$p$ value } & \multirow[b]{2}{*}{ OR } & \multicolumn{2}{|l|}{$95 \% \mathrm{Cl}$} \\
\hline & & & & & & & Lower & Upper \\
\hline Take alcohol & -1.475 & 0.634 & 5.407 & 1 & 0.020 & 0.229 & 0.066 & 0.793 \\
\hline $\begin{array}{l}\text { Body mass } \\
\text { index }\end{array}$ & -0.085 & 0.037 & 5.198 & 1 & 0.023 & 0.919 & 0.855 & 0.988 \\
\hline Constant & 1.911 & 1.064 & 3.228 & 1 & 0.072 & 6.762 & & \\
\hline
\end{tabular}

broadcast programmes facilitated by health professionals. In addition, a majority $(86.5 \%)$ indicated that the best way to remind them of their upcoming appointments was for this to be indicated on the patients' card.

\section{DISCUSSION}

The primary aim of this study was to investigate the association of lifestyle modification and pharmacological adherence on blood pressure control among patients with hypertension. The sample was drawn from patients with hypertension at a national referral hospital in Kenya. To address the main question, the following specific parameters were measured: clinical makers (blood 
pressure, heart rate and cholesterol levels); anthropometrics (BMI and waist circumference) (risk levels adjusted for gender); lifestyles habits (smoking, alcohol, dietary habits including vegetables, fruits, fast food and animal fat); pharmacological adherence and views on prevention, antihypertensive medication duration and adequacy of hypertension information. Our findings revealed that clinical, cholesterol and anthropometric measurements including blood pressure, heart rate, BMI, cholesterol, waist circumferences were abnormal. Blood pressure, heart rate and total cholesterol were higher in patient 50-59 years of age compared with other age categories. Females were observed to have higher BMI values compared with males; males were more likely to have smoked and consumed alcohol with those having higher educational level more likely to engage in this behaviour. Those who reported consuming alcohol had higher blood pressure values. Patients adhered to prescribed medications more than heart healthy lifestyle patterns, however only a small percentage consumed fast foods and meals with high animal fats. Daily vegetable and fruit consumption was associated with healthier levels for heart rate, BMI, blood pressure and cholesterol. Higher heart rates were associated with daily consumption of fast foods and meals high in animal fats. Of note, and critically important to prevention and management, hypertension was viewed as preventable only by a few respondents; most patients had inaccurate or incomplete information on what to do with their medication once their blood pressure was controlled. Additionally, respondents believed that the available hypertension-related information was inadequate, that dissemination of hypertension-related information should preferably be through radio programmes facilitated by medical experts and that reminders for appointments should be recorded on the patients' cards. These findings inform the narrative discussion below.

The study sample exhibited abnormal clinical-anthropometric parameters including systolic and diastolic blood pressure, heart rate, BMI, waist circumference and total cholesterol consistent with the diagnosis of hypertension and associated cardiometabolic risk factors. These abnormal levels are consistent with known association between the variables and hypertension. ${ }^{34-36}$ Patients aged 50-59 years showed substantially higher blood pressure, heart rate and cholesterol relative to other age categories. This is difficult to explain given that these physiological

Table 7 Respondents with higher educational level and those who are single view hypertension as preventable

\begin{tabular}{|c|c|c|c|c|c|}
\hline \multirow[b]{2}{*}{ Variable } & \multicolumn{3}{|c|}{ Thinks hypertension can be prevented } & \multirow[b]{2}{*}{ n (\%) } & \multirow[b]{2}{*}{$P$ value } \\
\hline & Yes (\%) & No (\%) & Do not know (\%) & & \\
\hline Age (years) & & & & & 0.242 \\
\hline$\leq 49$ & $33(35.9)$ & $27(29.3)$ & $32(34.8)$ & $92(100)$ & \\
\hline $50-59$ & 19 (32.2) & 12 (20.3) & $28(47.5)$ & $59(100)$ & \\
\hline$\geq 60$ & $17(23.3)$ & $22(30.1)$ & $34(46.6)$ & $73(100)$ & \\
\hline Gender & & & & & 0.501 \\
\hline Male & $28(27.7)$ & $31(30.7)$ & 42 (41.6) & $101(100)$ & \\
\hline Female & 41 (33.3) & $30(24.4)$ & 52 (42.3) & $123(100)$ & \\
\hline Education & & & & & 0.001 \\
\hline Illiterate & $3(11.1)$ & $6(22.2)$ & $18(66.7)$ & $27(100)$ & \\
\hline Primary & $24(25.8)$ & 25 (26.9) & $44(47.3)$ & $93(100)$ & \\
\hline Secondary & 24 (32.9) & $22(30.1)$ & 27 (37.0) & $73(100)$ & \\
\hline Tertiary & $18(58.1)$ & $8(25.8)$ & $5(16.1)$ & $31(100)$ & \\
\hline Marital status & & & & & $0.026^{*}$ \\
\hline Single & $6(75.0)$ & $0(0.0)$ & $2(25.0)$ & $8(100)$ & \\
\hline Married & $50(30.9)$ & $51(31.5)$ & $61(37.7)$ & $162(100)$ & \\
\hline Widowed & $9(24.3)$ & $6(16.2)$ & $22(59.5)$ & $37(100)$ & \\
\hline Divorced/separated & $4(23.5)$ & $4(23.5)$ & $9(52.9)$ & $17(100)$ & \\
\hline Religion & & & & & 0.821 \\
\hline Protestant & 39 (29.1) & $35(26.1)$ & $60(44.8)$ & $134(100)$ & \\
\hline Catholic & $28(34.1)$ & $23(28.0)$ & $31(37.8)$ & $82(100)$ & \\
\hline Muslim & $2(25.0)$ & $3(37.5)$ & $3(37.5)$ & $8(100)$ & \\
\hline Total & $69(30.8)$ & $61(27.2)$ & $94(42.0)$ & 229 (100) & \\
\hline
\end{tabular}

The values in bold emphasise where the $p$-value is statistically significant, that is less than 0.05 .

Demographic characteristics of the respondents in relation to their view on hypertension prevention.

Analysis with $\mathrm{X}^{2}$ test of independence; Fisher's exact test. 
Table 8 Respondents with higher education viewed hypertension-related information as inadequate

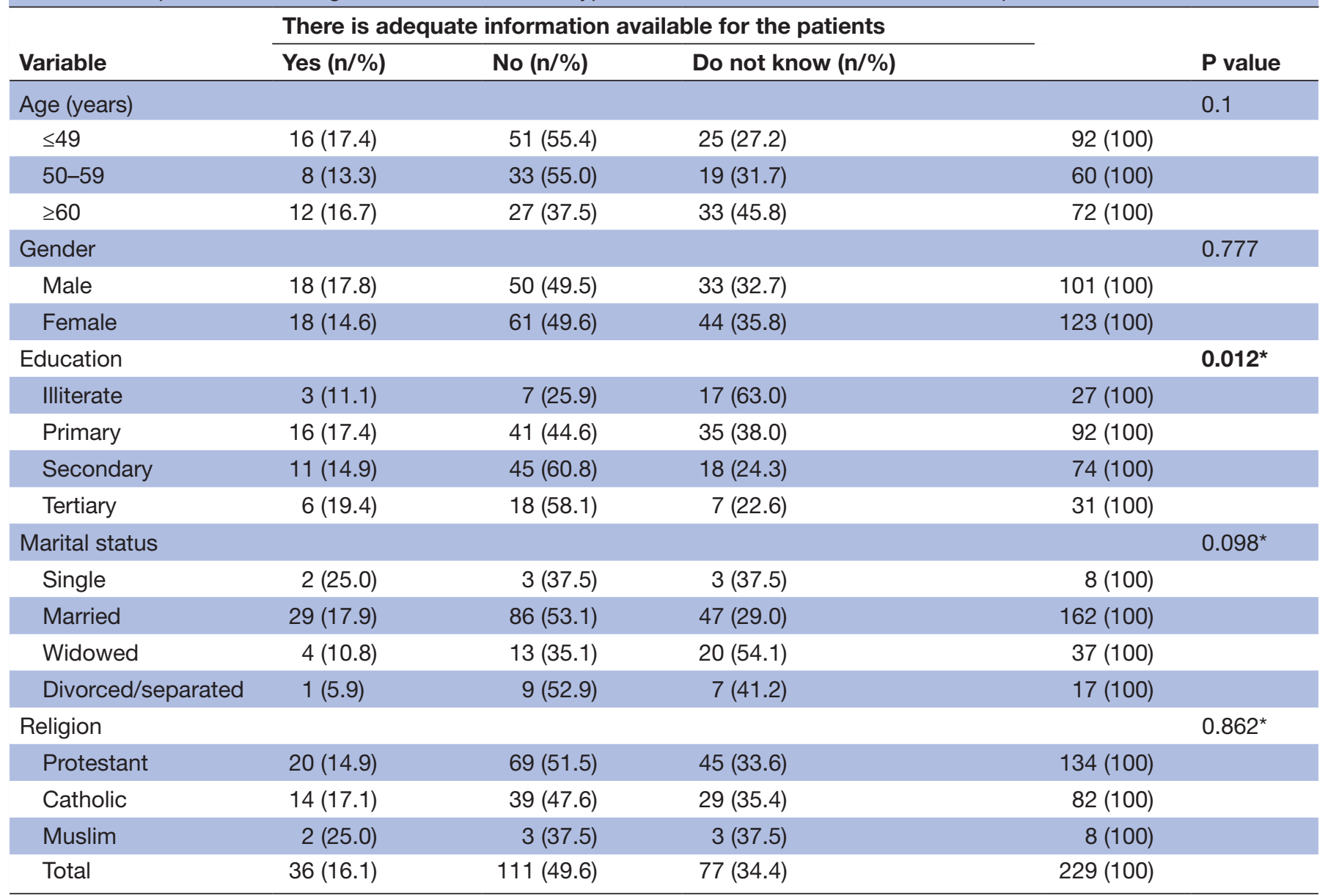

The values in bold emphasise where the $p$-value is statistically significant, that is less than 0.05 .

*Demographic characteristics of the respondents in relation to their view on availability of adequate information on hypertension. Analysis with $\mathrm{X}^{2}$ test of independence; Fisher's exact test.

parameters ordinarily increase with age, more so from 45 years among men and 55 years in women, respectively, ${ }^{37}$ but similar findings were posted recently from studies conducted in China. ${ }^{34}$ It is worth noting that the reference group is different with unique demographic characteristics, with only hypertension-related risk factors as the common denominator. ${ }^{6}{ }^{8}$ In this study, females had higher BMI measures and rates of obesity (BMI $\geq 30 \mathrm{~kg}$ / $\mathrm{m}^{2}$ ) compared with their male counterparts; similar findings have been shown in other Kenyan studies. ${ }^{38}$ Additionally, in studies from other countries, obesity is more prevalent in women $(14 \%)$ than men $(14 \%$ vs $10 \%) .{ }^{34} 38$ The gender difference can be explained by differences in the body muscle-fat composition, and lower activity levels in females, ${ }^{34}$ as well as accessibility to food stuffs while shopping, preparation and cooking.

Men reported higher rates of smoking and consuming alcohol compared with their female counterparts and men with higher educational attainment were more likely to consume alcohol. Importantly, those who consumed alcohol were observed to have higher blood pressure values. The higher rate of smoking among males compared with females is consistent with the findings of the Kenya Global Adult Tobacco Survey, ${ }^{39}$ which found males $(19.1 \%)$ to have smoked more than females $(4.5 \%)$. Globally, approximately $40 \%$ of men smoke compared with only $9 \%$ of women. ${ }^{8}$ Encouragingly, the magnitude of smoking in Kenya is low compared with the western prevalence and pattern. ${ }^{38}$ Those who smoke were observed to have higher blood pressure values consistent with findings of the prevalence of hypertension among military personnel in Kenya who smoked.$^{35}$ Smoking is associated with higher ambulatory blood pressure readings and the levels do not appear to reset to presmoking blood pressure levels after cessation, underscoring the long-term deleterious effect of smoking. ${ }^{40}$ Indeed, the duration of smoking is directly related to the diagnosis of hypertension despite smoking cessation. ${ }^{41}$ The mechanism by which smoking is related to elevated risk for developing hypertension is attributed to nicotine (the active ingredient of tobacco-related products) and its active role in activating the sympathetic nervous system and the resultant arterial stiffness. ${ }^{42} 43$

Related to the aforesaid, men, more so than women, are exposed to environments where smoking and alcohol consumption is accepted. Women's lives are 
Table 9 Radio broadcast programmes facilitated by health professionals were preferred for disseminating hypertensionrelated information

\begin{tabular}{lcc}
\hline Components & Frequency & $\begin{array}{l}\text { Per cent } \\
(\mathbf{\%})\end{array}$ \\
\hline Once blood pressure is controlled one should stop taking & drugs \\
Yes & 120 & 53.6 \\
No & 62 & 27.7 \\
Do not know & 42 & 18.8 \\
Total & 224 & 100.0
\end{tabular}

Best way health workers can convey medical information to the public

\begin{tabular}{lrr}
\hline Posters & 13 & 7.7 \\
\hline Print media & 34 & 20.1 \\
\hline Radio & 110 & 65.1 \\
\hline Television & 12 & 7.1 \\
\hline Total & $\mathbf{1 6 9}$ & 100.0 \\
\hline $\begin{array}{l}\text { Best ways patients can be reminded of appointments } \\
\text { Writing on the card }\end{array}$ & 192 & 86.5 \\
$\begin{array}{l}\text { Reminder short text messages on the } \\
\text { phone }\end{array}$ & 20 & 9.0 \\
$\begin{array}{l}\text { Calling the patients 1 day before } \\
\text { appointment }\end{array}$ & 10 & 4.5 \\
\hline Total & $\mathbf{2 2 2}$ & 100.0 \\
\hline
\end{tabular}

The values in bold emphasise where the p-value is statistically significant, that is less than 0.05 .

Respondents views on dissemination of information regarding management of hypertension.

often governed by traditional and cultural expectations for modesty behaviour, typically limiting or prohibiting drinking and smoking and their role as mothers and stewards of the family health further distance them from smoking and consuming alcohol. In addition, physiologically, alcohol tolerance capacity is lower in women due to reduced rates of gastric alcohol metabolism compared with men, ${ }^{44}$ and smaller volumes of body water in which alcohol is distributed, ${ }^{45}{ }^{46}$ resulting in less alcohol having an enhanced effect. It has also been reported that women are more prone to unpleasant acute effects from alcohol (eg, hangovers) ${ }^{47}$ relative to men, ${ }^{48}{ }^{49}$ characteristics which might inhibit women's drinking. Interestingly, we observed the association between alcohol consumption and higher educational level. Individuals with higher educational attainment may be at higher risk of alcohol consumption because of relatively higher income. Additionally, because of prolonged years of schooling and exposure to drinking environments, many men commence alcohol consumption while schooling due to peer pressure and stress. Similar patterns, with some differences, have been shown in other countries. Studies show alcohol consumption is disproportionately higher in males compared with females with some association with socioeconomic differentials. For example, in the USA, drinking is associated with lower educational levels among men, but higher educational levels among women; among the Korean, alcohol consumption is associated with being without partner among women; while in Australia, drinking is associated with higher income. ${ }^{50}$ Although these studies were conducted in western countries, parallels and differences can help shape the Kenyan approach to tobacco and alcohol consumption.

Of note, patients who reported consumption of alcohol were more likely to have higher blood pressure values. The results are consistent with the WHO report ${ }^{51}$ linking alcohol consumption to raised blood pressure values. Locally, beer and spirits consumption have been linked to hypertension among Military personnel, ${ }^{35}$ consistent with this and other studies. ${ }^{52}$ Indeed, a direct relationship between frequency and/or amount of alcohol and hypertension is already established. ${ }^{53}$ Of note, among heavy drinkers, it has been observed that systolic blood pressure is more likely to be elevated than diastolic blood pressure; findings that have implications for our patients. ${ }^{54}$ The association between elevations in blood pressure and alcohol consumption provides a strong rationale for why patients with hypertension should be counselled on being careful with alcohol. ${ }^{55}$ The mechanism of alcohol-related elevated blood pressure is poorly understood. However, augmentation of catecholamine and vasopressin-related vasoconstriction with resultant inhibition of endothelium-dependent vasodilatation has been proposed as one explanation for this association. ${ }^{56}$ Conversely, reduction in alcohol consumption have been shown to cause a reduction in both systolic and diastolic blood pressure. ${ }^{57}$ Furthermore, loss of relaxation as a result of inflammation and oxidative injury to the endothelium by angiotensin II leading to inhibition of endothelium-dependent nitric oxide production appears to be a pathway for alcohol-induced hypertension. ${ }^{58}$

Nutritionally, patients who consumed vegetables and fruits on a daily basis had lower heart rates, BMI, blood pressure and cholesterol levels. However, those who consumed fast foods and meals high in animal fats daily were observed to have increased heart rate. This suggests the protective or healthy nature of vegetables and fruits to the cardiovascular system. Vegetables and fruits have been reported to have cardioprotective properties, ${ }^{52}$ while animal products are associated with risk for cardiovascular metabolic diseases. ${ }^{5-61}$ Indeed, frequent consumption of vegetables and fruits is associated with an inverse relationship to cardiovascular diseases, while meat that is high in saturated fat is directly linked with cardiovascular-related mortality. ${ }^{59}$ Studies have shown that fruits and vegetables moderate the risk for hypertension, ${ }^{52}{ }^{62}$ reduce systolic blood pressure ${ }^{60}$ and slow the rise in both systolic and diastolic blood pressure over time ${ }^{63}$ Consumption of recommended servings of vegetables and fruits facilitate weight loss and lower BMI, as well as reducing the workload on the heart. ${ }^{626465}$ One explanation for this observed association is because of low energy density, high water, fibre and low fat content in the fruits and vegetables. Moreover, the high-fibre content is attributed to weight loss through the feeling of fullness or enhanced satiety 
without additional calories. On the other hand, fast foods and diets high in calories, but lacking fruits and vegetables, are associated with weight gain. ${ }^{66}$ Additionally, vegetables and fruits may lower blood pressure due to their high flavonoids content. The flavonoids have been reported to exhibit cardioprotective properties such as antioxidant, anti-inflammatory and induction of apoptotic effects, ${ }^{67-70}$ reducing cardiovascular mortality. ${ }^{71}$ Furthermore, vegetables and fruits are rich in potassium, an important factor in the regulation of blood pressure. When dietary potassium is low, sodium retention is increased with resultant increased blood pressure ${ }^{72}$ Conversely, with high dietary potassium, the kidneys excrete more salt and water, thus decreasing the blood pressure as well as the heart rate. ${ }^{73}$

Among our patients, adherence to antihypertensive medications was observed to be higher than adhering to heart healthy lifestyle patterns. High rates of adherence to antihypertensive medications is encouraging, given the importance of pharmacological therapy to achieving blood pressure control, prevention against complications and deleterious outcomes. ${ }^{74}$ However, the effect and control may be suboptimal since both pharmacological and non-pharmacological (lifestyle) interventions should complement each other for maximum benefit. This is consistent with findings among patients with hypertension from Ethiopian hospitals that showed overall lifestyle adherence at $23 \%$ while adherence to diet was at $69 \%{ }^{75}$ Heart healthy lifestyle patterns are reported to positively impact hypertension control as well as weight loss, dietary sodium restriction, alcohol moderation and enhanced regular exercise. ${ }^{76-80}$ As opposed to drug therapy, lifestyle modifications provided additional benefits beyond blood pressure reduction such as favourable effects on weight, fitness and cholesterol levels. ${ }^{79}$ Thus, experts recommend all patients with hypertension be given heart healthy lifestyle recommendations whether or not they are on pharmacological treatment. ${ }^{81}$ It has been shown that patients with the highest systolic blood pressure were more likely to report only medication recommendation/adherence while those with the lowest systolic blood pressure were more likely to report only lifestyle modification recommendation/adherence. ${ }^{82}$ Adherence to hypertension treatment decreases over time as reported in a large European study with $42 \%$ of participants stopping their medication within a year after diagnosis, ${ }^{83}$ while in a follow-up 10-year study, additional patients stopped taking their antihypertensive medication every year of the study. ${ }^{84}$ Adherence to dietary recommendations is reported to be much lower than adherence to antihypertensive medication..$^{85} 86$

Surprisingly, in our study, very few patients thought the condition was preventable, although those who reported single marital status and having higher educational attainment were more likely to endorse hypertension as a preventable disease than their counterparts. Our population is more familiar with the treatment of communicable and perhaps this finding reflects the approach to communicable diseases where once the desired outcome is achieved the medication is discontinued. Nonetheless, it is a compelling reason for the healthcare system to improve efforts to raise awareness on the chronic nature of hypertension treatment. The inaccurate and incomplete understanding of factors associated with prevention of hypertension provides an important window of opportunity for understanding the gaps in adherence to hypertension treatment and can help guide mitigation mechanisms. Individuals who reported being single (unmarried) and having higher educational attainment may perceive the risk of hypertension on their health to be high, prompting them to search for information on healthy living as well as to expert help. ${ }^{87} 88$ Other studies have observed that perceived risk is one of the key factors associated with promoting healthy behavioural changes, with those perceiving risk for some adverse event more likely to take preventive action. ${ }^{89}$ Individuals in our study with higher educational attainment exhibit higher knowledge regarding prevention of diseases than individuals with lower educational attainment. Education raises awareness of health promotion and prevention including risk factors, and healthy lifestyle behaviours including early screening. Studies have reported that hypertension and its risk factors are relatively unknown to people of lower education level. ${ }^{90}$ Our findings mirror a report regarding hypertension among Kenyan military personnel in which those of higher educational level practised healthier lifestyle behaviours compared with individuals with low educational attainment. ${ }^{35}$ Additionally, higher educational attainment is associated with higher socioeconomic status-a factor linked to disease awareness and health seeking behaviours. ${ }^{87} 8891$ Being single however, may provide an opportunity for seeking health tips with resultant health awareness, and participation in health-related activities, for example, reading healthy literature, exercises or watching health messages compared with married individuals who are busy with family matters including their children and spouse. Participants in our study who reported higher education attainment felt that publicly available information on hypertension prevention and treatment was inadequate, preferred its dissemination through radio by healthcare experts and wished reminders of upcoming appointments should be made on their patient cards. Education has been reported to be a proxy or marker of socioeconomic status. ${ }^{92}$ Thus, higher educational level is likely associated with higher income status facilitating ownership of internet and internet-enabled electronics which in turn may increase access to health-related activities. Improved access can boost knowledge and compliment the expert-shared messages. These findings are consistent with reports where patients wanted advice from healthcare professionals to avoid 'self-harm', and felt doctors and nurses did not provide enough information and thus looked for information from other sources such as the web, media or medical magazines. ${ }^{93}$ In addition, information given to patients when attending health messaging sessions at health facilities is often generic and meant 
to accommodate diverse educational backgrounds. This calls for healthcare professionals to step up and offer patient-centred individualised information based on patient needs. The recommendation for radio dissemination of hypertension-related information by medical experts underscores the important role played by radio and the health experts in sharing information about hypertension-related prevention and treatment. Indeed, there are numerous radio channels that can reach the majority of the population at relatively low cost to the individual. Additionally, most of the mobile phones in Kenya are radio frequency enabled meaning that they do not depend on internet access, minimising cost but ensuring wide coverage of information dissemination. The patients recognised many sources of information, but they recommended that experts should use the radio programmes to educate the public. This underscores the confidence patients have in health professionals and suggests that health experts have an obligation to participate in hypertension prevention/awareness as well as treatment. It is also a wakeup call for health professionals to keep abreast with current best practices in hypertension-related issues and management. The professionals should make deliberate efforts towards educating the public on non-communicable diseases including hypertension. Awareness and educational messages by the health professional should clarify the false impression that 'taking hypertension-related medications should be stopped once the problem is controlled', a finding observed in this study. The messaging should include the complications that can be attributed to discontinuation of treatment including coronary and cerebral artery events such as myocardial infarction and strokes and their implications for the patient. Although drug discontinuation may be related to misconception and inadequate information, other factors, for example, lack of finances to buy the drugs may also have a role in non-adherence. In this regard, policy makers should be lobbied to allow health insurance to pay for antihypertensive medications and investment in availing cheap generic quality brands. Additionally, the health education model should mirror approaches adopted for the prevention and management of HIV/AIDs, where people were flooded with HIV/AIDs messages that bore very promising results. Thus, communication and health messages on risk factors, management and prevention of non-communicable diseases need to be amplified through such messaging to realise success.

There are several limitations to our study. The assessment of smoking, alcohol consumption, dietary adherence and medication adherence were cross-sectional, conducted at one point in time by asking patterns of patient practices and habits. Self-reported health behaviour patterns and practices captured at one point in time may not fully capture the person's lifestyle as patterns may vary over time. This is a limitation of cross-sectional designs, but the findings are temporally related to the clinical and anthropometric measures reported in the study which adds to our confidence in the results. In addition, the data may have suffered from recall bias as patients sought to recall health behaviour patterns. The findings from this study will inform the next study to be conducted to answer this important question. Medication compliance was self-reported by questionnaire and not verified using biological markers. Medication reconciliation with the medical record and pill count enhanced the rigour but did not fully eliminate the potential for the error. The study also did not assess salt intake, stress and activity profiles which are important components in hypertension risk assessment. Finally, although we showed important associations this was a cross-sectional descriptive study which precludes our ability to make causal inferences. In addition, the small sample size may not have power to detect statistical difference between some variables where we showed clinically relevant associations.

In conclusion, findings from this study revealed advanced age was associated with missed targets for hypertension-related risk factors and blood pressure goals. Female gender, fast food and animal fats were associated with missed target for hypertension-related risks. Smoking and alcohol consumption was higher in males, especially those of higher educational attainment. Alcohol consumption was associated with poor blood pressure control. Daily intake of vegetables and fruits were associated with healthier levels of blood pressure, BMI, heart rate and cholesterol levels. Although pharmacological adherence was adequate suboptimal blood pressure control was observed requiring the addition of heart healthy lifestyle modification as part of the treatment plan. A small proportion of participants considered hypertension as preventable. This presents a compelling mandate to address modifiable risk factors by prescribing heart healthy lifestyle behaviours and antihypertensive medication adherence through locally tailored, expert delivered hypertension-related information and treatment.

Acknowledgements The authors would like to thank all study participants who took part in the study as well as Professor Eileen Stuart-Shor for her technical assistance with the manuscript editing.

Contributors SK, WM and MC conceptualised and designed the study and drafted the article. SK, OTO and SM acquired the data, carried out the analysis and interpretation of the data and participated in drafting the article.

Funding This work was supported by funding from Kenyatta National Hospital research grant: $\mathrm{KNH} / 23 / 22$.

Competing interests None declared.

Patient consent for publication Obtained.

Ethics approval The study was reviewed and approved by Kenyatta National Hospital University of Nairobi Ethical Review Committee (KNH-UoN ERC) and institutional permission was granted by the head of the Department of Medicine.

Provenance and peer review Not commissioned; externally peer reviewed.

Data sharing statement The datasets used and analysed during the current study are available from the corresponding author on reasonable request.

Open access This is an open access article distributed in accordance with the Creative Commons Attribution Non Commercial (CC BY-NC 4.0) license, which permits others to distribute, remix, adapt, build upon this work non-commercially, and license their derivative works on different terms, provided the original work is properly cited, appropriate credit is given, any changes made indicated, and the use is non-commercial. See: http://creativecommons.org/licenses/by-nc/4.0/. 


\section{REFERENCES}

1. Danaei G, Lu Y, Singh G, et al. Cardiovascular disease, chronic kidney disease, and diabetes mortality burden of cardiometabolic risk factors from 1980 to 2010: a comparative risk assessment. Lancet Diabetes Endocrinol 2014;2:634-47.

2. Forouzanfar MH, Afshin A, Alexander LT, et al. Global, regional, and national comparative risk assessment of 79 behavioural, environmental and occupational, and metabolic risks or clusters of risks, 1990-2015: a systematic analysis for the Global Burden of Disease Study 2015. Lancet 2016;388:1659-724.

3. Zhou B, Bentham J, Di Cesare M, et al. Worldwide trends in blood pressure from 1975 to 2015: a pooled analysis of 1479 populationbased measurement studies with $19 \cdot 1$ million participants. The Lancet 2017;389:37-55.

4. Cappuccio FP, Micah FB, Emmett L, et al. Prevalence, detection, management, and control of hypertension in Ashanti, West Africa. Hypertension 2004;43:1017-22.

5. Olsen MH, Angell SY, Asma S, et al. A call to action and a lifecourse strategy to address the global burden of raised blood pressure on current and future generations: the Lancet Commission on hypertension. Lancet 2016;388:2665-712.

6. World Health Organization. A global brief on hypertension: silent killer, global public health crisis: World Health Day 2013. 40. Geneva, Switzerland: WHO Press, 2013.

7. Adeloye D, Basquill C. Estimating the prevalence and awareness rates of hypertension in Africa: a systematic analysis. PLoS One 2014;9:e104300.

8. World Health Organization. Global status report on noncommunicable diseases 2010. Geneva, Switzerland: World Health Organization 2011.

9. Tesfaye F. Epidemiology of cardiovascular disease risk factors in Ethiopia: the rural-ruban gradient. Epidemiologi och folkhälsovetenskap 2008.

10. Grosse-Tebbe S, Figueras J. Snapshots of health systems: the state of affairs in 16 countries in summer. Geneva, Switzerland: World Health Organization, 2004

11. Demmler KM, Klasen S, Nzuma JM, et al. Supermarket purchase contributes to nutrition-related non-communicable diseases in urban Kenya. PLoS One 2017;12:e0185148.

12. Kimenju SC, Rischke R, Klasen S, et al. Do supermarkets contribute to the obesity pandemic in developing countries? Public Health Nutr 2015;18:3224-33.

13. International Diabetes Federation. IDF Diabetes Atlas, 7th Edition (2015). 2015 https://www.idf.org/component/attachments/ attachments.html?id=1093\&task=download (Accessed 19 Mar 2018).

14. Olack B, Wabwire-Mangen F, Smeeth L, et al. Risk factors of hypertension among adults aged $35-64$ years living in an urban slum Nairobi, Kenya. BMC Public Health 2015;15:1251.

15. Poulter NR, Khaw KT, Hopwood BE, et al. The Kenyan Luo migration study: observations on the initiation of a rise in blood pressure. BMJ 1990;300:967-72.

16. Addo J, Smeeth L, Leon DA. Hypertension in sub-saharan Africa: a systematic review. Hypertension 2007;50:1012-8.

17. Doulougou B, Kouanda S, Rossier C, et al. Differences in hypertension between informal and formal areas of Ouagadougou, a sub-Saharan African city. BMC Public Health 2014;14:893.

18. Kenya Healthcare Federation,. Task Force Health Care. Kenyan: Kenyan Healthcare Sector: Opportunities for the Dutch Life Sciences \& Health Sector, 2016.

19. Ministry of Health. Kenya Health Policy 2014-2030: towards attaining the highest standard of health. 2014 http://publications. universalhealth2030.org/uploads/kenya_health_policy_2014_to_ 2030.pdf (Accessed 4 Aug 2018).

20. Ataklte F, Erqou S, Kaptoge S, et al. Burden of undiagnosed hypertension in sub-saharan Africa: a systematic review and metaanalysis. Hypertension 2015;65:291-8.

21. Dzudie A, Kengne AP, Muna WF, et al. Prevalence, awareness, treatment and control of hypertension in a self-selected sub-Saharan African urban population: a cross-sectional study. BMJ Open 2012;2:e001217.

22. Ogah OS, Rayner BL. Recent advances in hypertension in subSaharan Africa. Heart 2013;99:1390-7.

23. Appel LJ. Lifestyle modification: is it achievable and durable? The argument for. J Clin Hypertens 2004;6:578-81.

24. Dickinson HO, Mason JM, Nicolson DJ, et al. Lifestyle interventions to reduce raised blood pressure: a systematic review of randomized controlled trials. J Hypertens 2006;24:215-33.

25. Baena CP, Olandoski M, Younge JO, et al. Effects of lifestyle-related interventions on blood pressure in low and middle-income countries: systematic review and meta-analysis. J Hypertens 2014;32:961-73.
26. Lelong $\mathrm{H}$, Galan P, Kesse-Guyot $\mathrm{E}$, et al. Relationship between nutrition and blood pressure: a cross-sectional analysis from the nutrinet-santé study, a french web-based cohort study. Am J Hypertens 2015;28:362-71.

27. Vamvakis A, Gkaliagkousi E, Triantafyllou A, et al. Beneficial effects of nonpharmacological interventions in the management of essential hypertension. JRSM Cardiovasc Dis 2017;6:204800401668389.

28. Tocci G, Borghi C, Volpe M. Clinical management of patients with hypertension and high cardiovascular risk. High Blood Pressure \& Cardiovascular Prevention 2014;21:107-17.

29. Wong GWK, Laugerotte A, Wright JM. Blood pressure lowering efficacy of dual alpha and beta blockers for primary hypertension. Cochrane Database Syst Rev 2015;1.

30. Poulter NR, Prabhakaran D, Caulfield M. Hypertension. The Lancet 2015;386:801-12.

31. Mugenda OM, Mugenda AG. Research methods: quantitative and qualitative approaches. Nairobi: African Centre for Technology Studies (ACTS), 2003.

32. National Institutes of Health. Diet history questionnaire. 2018 https:// aghealth.nih.gov/collaboration/qx/dhq.pdf (Accessed 4 Aug 2018).

33. International Diabetes Federation. The IDF consensus worldwide definition of the metabolic syndrome. 2009 https://www.pitt.edu/ super1/Metabolic/IDF1.pdf (Accessed 4 Aug 2018).

34. Zhang Q, Mahapatra T, Huang F, et al. Association between Anthropometric Measures and Indicators for Hypertension Control among Kazakh-Chinese hypertension patients in Xinjiang, China: results from a cross-sectional study. PLoS One 2017;12:e0170959.

35. Mundan V, Muiva M, Kimani S. Physiological, behavioral, and dietary characteristics associated with hypertension among Kenyan defence forces. ISRN Prev Med 2013;2013:1-8.

36. Gelber RP, Gaziano JM, Manson JE, et al. A prospective study of body mass index and the risk of developing hypertension in men. Am $J$ Hypertens 2007;20:370-7.

37. Pearson JD, Morrell CH, Brant LJ, et al. Age-associated changes in blood pressure in a longitudinal study of healthy men and women. $J$ Gerontol A Biol Sci Med Sci 1997;52A:M177-M183.

38. Muchira J, Stuart-Shor E, Kariuki J, et al. Distribution and characteristics of risk factors for cardiovascular-metabolic disease in a rural Kenyan community. International Journal of Africa Nursing Sciences 2015;3:76-81.

39. GATS. Global adult tobacco survey. 2014 https://www. tobaccofreekids.org/assets/global/pdfs/en/GATS_Kenya_Fact Sheet_2014.pdf (Accessed 19 Mar 2018).

40. Mancia G, De Backer G, Dominiczak A, et al. 2007 Guidelines for the management of arterial hypertension: The Task Force for the Management of Arterial Hypertension of the European Society of Hypertension (ESH) and of the European Society of Cardiology (ESC). Eur Heart J 2007;28:1462-536.

41. Wenzel D, Souza JM, Souza SB. Prevalence of arterial hypertension in young military personnel and associated factors. Rev Saude Publica 2009;43:789-95.

42. Parikh NI, Pencina MJ, Wang TJ, et al. A risk score for predicting near-term incidence of hypertension: the framingham heart study. Ann Intern Med 2008;148:102-10.

43. Bowman TS, Gaziano JM, Buring JE, et al. A prospective study of cigarette smoking and risk of incident hypertension in women. $\mathrm{J} A m$ Coll Cardiol 2007;50:2085-92.

44. Finucane MM, Stevens GA, Cowan MJ, et al. National, regional, and global trends in body-mass index since 1980: systematic analysis of health examination surveys and epidemiological studies with 960 country-years and 9.1 million participants. Lancet 2011;377:557-67.

45. Baraona E, Abittan CS, Dohmen K, et al. Gender differences in pharmacokinetics of alcohol. Alcoholism: Clinical and Experimental Research 2001;25:502-7.

46. Thomasson H. Gender differences in alcohol metabolism. Physiological responses to ethanol. Galanter M, ed. Recent dev alcohol. New York: Kluwer Academic / Plenum Publishers, 1995:163-79.

47. Mirand AL, Welte JW. Total body water adjustment of mean alcohol intakes. J Subst Abuse 1994;6:419-25.

48. York JL, Welte JW. Gender comparisons of alcohol consumption in alcoholic and nonalcoholic populations. J Stud Alcohol 1994;55:743-50.

49. Slutske WS, Piasecki TM, Hunt-Carter EE. Development and initial validation of the Hangover Symptoms Scale: prevalence and correlates of Hangover Symptoms in college students. Alcohol Clin Exp Res 2003;27:1442-50.

50. Hill EM, Chow K. Life-history theory and risky drinking. Addiction 2002;97:401-13. 
51. World Health Organization. Global health risks: mortality and burden of disease attributable to selected major risks. Geneva, Switzerland: World Health Organization, 2009.

52. Núñez-Córdoba JM, Martínez-González MA, Bes-Rastrollo M, et al. Alcohol Consumption and the Incidence of Hypertension in a Mediterranean Cohort: The SUN Study. Revista Española de Cardiología 2009;62:633-41.

53. Fuchs FD, Chambless LE, Whelton PK, et al. Alcohol consumption and the incidence of hypertension: The Atherosclerosis Risk in Communities Study. Hypertension 2001;37:1242-50.

54. Husain K, Ansari RA, Ferder L. Alcohol-induced hypertension: mechanism and prevention. World J Cardiol 2014;6:245.

55. Rosenblitt JC, Soler H, Johnson SE, et al. Sensation seeking and hormones in men and women: exploring the link. Horm Behav 2001;40:396-402.

56. Kawano Y. Physio-pathological effects of alcohol on the cardiovascular system: its role in hypertension and cardiovascular disease. Hypertens Res 2010;33:181-91.

57. Xin X, He J, Frontini MG, et al. Effects of alcohol reduction on blood pressure: a meta-analysis of randomized controlled trials. Hypertension 2001;38:1112-7.

58. Puddey IB, Beilin LJ. Alcohol is bad for blood pressure. Clin Exp Pharmacol Physiol 2006;33:847-52.

59. Harriss LR, English DR, Powles J, et al. Dietary patterns and cardiovascular mortality in the Melbourne collaborative cohort study. Am J Clin Nutr 2007;86:221-9.

60. Appel LJ, Brands MW, Daniels SR, et al. Dietary approaches to prevent and treat hypertension: a scientific statement from the American Heart Association. Hypertension 2006;47:296-308.

61. de Ramirez SS, Enquobahrie DA, Nyadzi G, et al. Prevalence and correlates of hypertension: a cross-sectional study among rural populations in sub-Saharan Africa. $J$ Hum Hypertens 2010;24:786-95.

62. Utsugi MT, Ohkubo T, Kikuya M, et al. Fruit and vegetable consumption and the risk of hypertension determined by self measurement of blood pressure at home: the Ohasama study. Hypertens Res 2008;31:1435-43.

63. Miura K, Greenland P, Stamler J, et al. Relation of vegetable, fruit, and meat intake to 7-year blood pressure change in middleaged men: the Chicago Western Electric Study. Am J Epidemiol 2004;159:572-80.

64. Vrieze A, Holleman F, Zoetendal EG, et al. The environment within: how gut microbiota may influence metabolism and body composition. Diabetologia 2010;53:606-13.

65. Bertoia ML, Mukamal KJ, Cahill LE, et al. Changes in intake of fruits and vegetables and weight change in united states men and women followed for up to 24 years: analysis from three prospective cohort studies. PLoS Med 2015;12:e1001878.

66. World Health Organization. Prevention of cardiovascular disease: pocket guidelines for assessment and management of cardiovascular risk. Geneva, Switzerland: World Health Organization, 2007.

67. Erdman JW, Balentine D, Arab L, et al. Flavonoids and heart health: proceedings of the ILSI North America Flavonoids Workshop, May 31-June 1, 2005, Washington, DC. J Nutr 2007;137:718S-37.

68. Yochum L, Kushi LH, Meyer K, et al. Dietary flavonoid intake and risk of cardiovascular disease in postmenopausal women. Am J Epidemiol 1999;149:943-9.

69. Arts IC, Hollman PC. Polyphenols and disease risk in epidemiologic studies. Am J Clin Nutr 2005;81:317S-25.

70. Hooper L, Kroon PA, Rimm EB, et al. Flavonoids, flavonoid-rich foods, and cardiovascular risk: a meta-analysis of randomized controlled trials. Am J Clin Nutr 2008;88:38-50.

71. Mink PJ, Scrafford CG, Barraj LM, et al. Flavonoid intake and cardiovascular disease mortality: a prospective study in postmenopausal women. Am J Clin Nutr 2007;85:895-909.

72. Rheinschild E. Fruit and veggies rich in potassium may be key to lowering blood pressure. $2017 \mathrm{https} / / /$ news.usc.edu/119637/how-tolower-your-blood-pressure-eat-more-fruit-and-veggies/ (Accessed 20 Mar 2018).
73. World Health Organization. Potassium intake for adults and children: guideline. Geneva: World Health Organization, 2012.

74. Feldman R, Bacher M, Campbell N, et al. Adherence to pharmacologic management of hypertension. Can J Public Health 1998:89:116

75. Tibebu A, Mengistu D, Negesa L. Adherence to recommended lifestyle modifications and factors associated for hypertensive patients attending chronic follow-up units of selected public hospitals in Addis Ababa, Ethiopia. Patient Prefer Adherence 2017:11:323-30.

76. McGuire HL, Svetkey LP, Harsha DW, et al. Comprehensive lifestyle modification and blood pressure control: a review of the PREMIER trial. J Clin Hypertens 2004;6:383-90.

77. Sacks FM, Svetkey LP, Vollmer WM, et al. Effects on Blood Pressure of Reduced Dietary Sodium and the Dietary Approaches to Stop Hypertension (DASH) Diet. N Engl J Med Overseas Ed 2001;344:3-10.

78. Svetkey LP, Erlinger TP, Vollmer WM, et al. Effect of lifestyle modifications on blood pressure by race, sex, hypertension status, and age. J Hum Hypertens 2005;19:21-31.

79. Miller ER, Erlinger TP, Young DR, et al. Results of the Diet, Exercise, and Weight Loss Intervention Trial (DEW-IT). Hypertension 2002;40:612-8.

80. Stevens VJ, Obarzanek E, Cook NR, et al. Long-term weight loss and changes in blood pressure: results of the Trials of Hypertension Prevention, phase II. Ann Intern Med 2001;134:1-11.

81. Chobanian AV, Bakris GL, Black HR, et al. Seventh report of the joint national committee on prevention, detection, evaluation, and treatment of high blood pressure. Hypertension 2003;42:1206-52.

82. Lopez L, Cook EF, Horng MS, et al. Lifestyle modification counseling for hypertensive patients: results from the national health and nutrition examination survey 1999-2004. Am J Hypertens 2009;22:325-31.

83. Mazzaglia G, Mantovani LG, Sturkenboom MC, et al. Patterns of persistence with antihypertensive medications in newly diagnosed hypertensive patients in Italy: a retrospective cohort study in primary care. J Hypertens 2005;23:2093-100.

84. Van Wijk BL, Klungel OH, Heerdink ER, et al. Rate and determinants of 10 -year persistence with antihypertensive drugs. J Hypertens 2005;23:2101-7.

85. Galletti F, Agabiti-Rosei E, Bernini G, et al. Excess dietary sodium and inadequate potassium intake by hypertensive patients in Italy: results of the MINISAL-SIIA study program. $J$ Hypertens 2014;32:48-56.

86. De Nicola L, Minutolo R, Chiodini P, et al. Global approach to cardiovascular risk in chronic kidney disease: reality and opportunities for intervention. Kidney Int 2006;69:538-45.

87. Zhang X, Zhu M, Dib HH, et al. Knowledge, awareness, behavior $(\mathrm{KAB})$ and control of hypertension among urban elderly in western China. Int J Cardiol 2009;137:9-15.

88. Gee ME, Bienek A, McAlister FA, et al. Factors associated with lack of awareness and uncontrolled high blood pressure among Canadian adults with hypertension. Can J Cardiol 2012;28:375-82.

89. Kreuter MW, Strecher VJ. Changing inaccurate perceptions of health risk: results from a randomized trial. Health Psychol 1995;14:56-63.

90. Tedesco MA, Di Salvo G, Caputo S, et al. Educational level and hypertension: how socioeconomic differences condition health care. $J$ Hum Hypertens 2001;15:727-31.

91. Mills KT, Bundy JD, Kelly TN, et al. Global disparities of hypertension prevalence and control: a systematic analysis of population-based studies from 90 countries. Circulation 2016;134:441-50.

92. Colhoun HM, Hemingway H, Poulter NR. Socio-economic status and blood pressure: an overview analysis. J Hum Hypertens 1998;12:91-110.

93. National Clinical Guideline Centre. Hypertension: the clinical management of primary hypertension in adults: update of clinical guidelines 18 and 34. London, UK: National Clinical Guideline Centre, 2011:861. 